gabén früherer Untersucher, ${ }^{*}$ ) betreffend das Vorkommen kleinster Eiweissmengen im normalen Harn, bestätigt und durch neue Beobachtungen über ihr Verhalten zu Eiweissreagentien bereichert. Für die Anstellung: der wichtigeren Eiweissproben kommen dieselben nicht in Betracht, weshalb ich im Uebrigen auf das Original verweise.

Schätzung der Eiweissmenge im Harn mittelst des Esbachschen Albuminimeters. Dieses Instrument ist ein kleiner Glascylinder, welcher eine Marke trägt, bis zu welcher der zu untersuchende Eiweissharn, und darüber eine zweite Marke, bis zu welcher eine Lösung von 1 Theil Pikrinsäure und 2 Theilen Citronensäure in 100 Theilen Wasser aufzufüllen ist, um einen Eiweissniederschlag zu erhalten, aus dessen nach 24 Stunden sich ergebender Höhe mit Hülfe einer empirisch festgestellten Scala direct der Procentgehalt an Eiweiss erschlossen wird. Das sehr bequeme Verfahren ist von mehreren Seiten, so von J. E. Blomfield ${ }^{* *}$ ) and P. Gattman $n^{* * * *}$ ) in Anwendung gebracht und als für ärztliche Zwecke völlig genügend warm empfohlen worden. Nach Guttman $n$ gibt es gegen die Wägungsbestimmung höchstens Differenzen von $0,05 \%$ Eiweiss.

\title{
Die durch Pikrinsäure fällbaren Substanzen des normalen Harns
}

hat M. Jaffe, $\dagger$ ) veranlasst durch die Verwendung dieses Reagens' zum Eiweissnachweise, näher untersucht. Danach enthält der Niederschlag, welcher sich aus Menschenharn durch Zusatz von concentrirter wässriger Pikrinsäurelösung, reichlicher und schneller durch Eintragen der fein gepulverten Pikrinsäure bis nahe zur Sättigung ( $1 \mathrm{~g}$ auf $150 \mathrm{cc}$ Harn), oder Zufügung einer alkoholischen Lösung erhalten lässt, neben Harnsäure vorzugsweise eine krystallinische Doppelverbindung von pikrinsaurem Kreatinin mit pikrinsaurem Kalium. Dieselbe ist in kaltem Wasser schwer löslich. $100 c c$ Wasser von $19-20^{\circ} \mathrm{C}$. lösen davon $0,1806 \mathrm{~g}$. Versuche, die Verbindung zur quantitativen Bestimmung des Kreatinins zu benutzen, gaben kein befriedigendes Resultat.

Zum Nachweis von Blutfarbstoff im Harn eignet sich nach $\mathrm{C}$. Rosentha $1+\dagger$ ) von den vorhandenen Methoden die spectroskopische nur

*) Vergl. diese Zeitschrift 20, 162.

**) Lancet 1886, S. 153.

***) Berliner klin. Wochenschrift 1886, S. 117, No. 8.

†) Zeitschrift für physiol. Chemie 10, 391 .

††) Archiv für pathol. Anatomie von Virchow 103, 516. 